Reducing Hypoxia in an Urban Estuary Despite Climate Warming

Supplementary Information

Michael M. Whitney* and Penny Vlahos

Department of Marine Sciences

University of Connecticut

1080 Shennecossett Road

Groton, Connecticut 06340, United States

*Corresponding Author: Michael.Whitney@uconn.edu

1080 Shennecossett Road, Groton, Connecticut 06340, United States

Contents (11 total pages including 2 tables and 1 figure)

Detailed Materials and Methods

Table S1 Means and standard deviations of analyzed observations

Table S2 Multiple linear regression results

Figure S1 Multiple linear regression time series 


\section{Detailed Materials and Methods}

The NY and CT WWTP nitrogen loads from the Long Island Sound Study ${ }^{30}$ are "tradeequalized" loads that were calculated by first applying normalized transfer efficiency coefficients to each individual WWTP load before summing into the reported CT and NY WWTP nitrogen loads. The transfer efficiency coefficients are designed to account for attenuation before reaching the WLIS hypoxia area. Coefficients decrease eastward along LIS, decrease farther inland, and are small (0.11-0.21) for NYC WWTPs entering into the East River tidal strait (Figure 1) connecting LIS and the Hudson River. Despite small transfer efficiency coefficients, the large NYC WWTPs represent most of the calculated NY WWTP nitrogen load. Detailed descriptions and discussions of the "trade-equalized" loads are included in the LIS TMDL ${ }^{24}$ and on the Long Island Sound Study website. ${ }^{30}$

The methods for calculating the direct WLIS nitrogen load are detailed in Vlahos et al. ${ }^{31}$ This load includes direct atmospheric deposition on WLIS, inputs from local rivers within the WLIS watershed (these riverine inputs include loads from local WWTPs), and nitrogen loads associated with direct runoff from bordering coastal areas. The NYC WWTPs, which enter through the East River tidal strait (outside of WLIS), are not part of the direct WLIS nitrogen load. The ELIS + CLIS nitrogen load includes direct atmospheric deposition and terrestrial inputs from rivers and direct runoff within the ELIS and CLIS watersheds. The ELIS + CLIS nitrogen load is calculated with the methods described above for direct WLIS nitrogen load following Vlahos et al. ${ }^{31}$ March-August (six-month) averages are reported for the ELIS + CLIS nitrogen load.

River discharge entering from the LIS watershed is calculated based on data from 27 USGS stream gages (with non-overlapping gaged areas) following the methods described in 
Whitney et al. ${ }^{32}$ As in Deignan-Schmidt and Whitney, ${ }^{33}$ the watershed is first divided into basins for the largest river (Connecticut River), individual intermediate rivers (Thames, Housatonic, and Quinnipiac Rivers), and coastal watersheds with smaller rivers and direct runoff to LIS (Southeast, Southcentral, and Southwest basins). Discharge for each basin is calculated by summing observed daily discharge values for the stream gages within the basin and then scaling up by the ratio of basin area to total gaged area. Discharge for the Thames River, Connecticut River, and Southeast basins are combined for the ELIS discharge. The Quinnipiac, Housatonic, and Southcentral basins are combined for the CLIS discharge. The ELIS and CLIS discharge are combined to form the ELIS + CLIS discharge. The Southwest basin comprises the WLIS discharge. The ELIS + CLIS and WLIS river discharge then are averaged over the six-month period from March through August each year.

Wind forcing data are from the Sikorsky Memorial Airport in Bridgeport, CT (KDBR, Figure 1) following the approach in Lee and Lwiza; ${ }^{43}$ these data are from the NOAA National Climate Data Center. As in Lee and Lwiza, ${ }^{43}$ the July-August average of average daily wind speeds are analyzed. The July-August prevailing wind directions are calculated as the mode of the directions of the daily fastest 1-2 minute winds, since these are the wind directions available from the NOAA National Climate Data Center. Wind directions are expressed as the direction winds are blowing from, the meteorological convention.

Stations where water quality data are collected by the CT-DEEP on a bi-weekly to monthly basis year-round are shown in Figure 1. At each station, CT-DEEP measures water property profiles (temperature, salinity, dissolved oxygen, fluorometric chlorophyll $a$, and $\mathrm{pH}$ ) and collects near-surface and near-bottom water samples that are analyzed for nitrogen, 
phosphorus, silica, chlorophyll $a$, and suspended solids. ${ }^{34}$ Water densities are calculated from the temperature and salinity profiles. The buoyancy frequency squared $\left(N^{2}\right)$ is calculated as the vertical derivative of density multiplied by the negative of gravitational acceleration $\left(9.8 \mathrm{~m} \mathrm{~s}^{-2}\right)$ divided by a reference density $\left(1025 \mathrm{~kg} \mathrm{~m}^{3}\right)$. Chlorophyll $a$ profiles reflect the fluorometric profiles corrected with the near-surface and near-bottom water samples. Station A4 (Figure 1) is the primary analysis station for this study. The 25-year analysis period is 1994 (the beginning of monitoring at Station A4) to 2018 (the most recent year available in the lisicos.uconn.edu database at time of analysis).

Near-bottom and near-surface temperatures, salinities, and oxygen observations (including concentrations of dissolved oxygen, oxygen saturation, and AOU) are reported for August at station A4 and calculated from the shallowest and deepest measurements in vertical profiles. The buoyancy frequency squared is calculated for August at the same station in two ways: bulk $N^{2}$ calculated from the difference between near-surface and near-bottom densities and upper-quartile $N^{2}$ calculated from the stratification distribution throughout the water column to characterize stratification in the pycnocline. August chlorophyll concentrations for the upper half of the water column at station A4 are reported. February-May chlorophyll concentrations averaged over all depths and averaged throughout LIS also are reported to follow the approach Lee and Lwiza ${ }^{43}$ used to characterize spring productivity and its connections with hypoxia. Total nitrogen at station A4 are reported as March-August (sixmonth) average concentrations to pair with the averaging applied to river discharge.

Annual maximum hypoxic areas are the values reported by the Long Island Sound Study. ${ }^{37}$ As in Lee and Lwiza, ${ }^{43}$ annual maximum hypoxic volumes are calculated by first 
interpolating oxygen profile data (at CT-DEEP stations, Figure 1) onto a regular grid covering LIS and then calculating the volume of all waters with dissolved oxygen concentrations below $3 \mathrm{mg}$ $\mathrm{L}^{-1}$. The interpolation grid used in the present study is the same as the model grid described in Jia and Whitney ${ }^{55}$ and Vlahos et al. ${ }^{31}$ Several interpolation methods were pursued (e.g. nearest neighbor, linear, inverse distance at various powers, and optimal interpolation). Inverse distance squared weighting was selected because hypoxic volume results most closely matched Lee and Lwiza ${ }^{43}$ results for the ten overlapping years (1995-2004). The newly calculated hypoxic volumes are almost perfectly correlated with the original Lee and Lwiza ${ }^{43}$ values $\left(r^{2}=0.98\right)$ and the root-mean-square error is $12 \%$ of the standard deviation of the hypoxic volumes. Calculated hypoxic areas and volumes both depend heavily on the sampling station configuration and interpolation methods, but trends can be discerned as long as the same methods are applied throughout the time series. Station locations have remained fixed throughout the analysis period, but the number of stations occupied during summer mappings varies from 36 to 52 . This varying number of stations sampled can introduce some variability in the calculated hypoxic areas and volumes, though the station coverage tends to be about the same near the hypoxia boundaries. All other aspects of the hypoxic area and volume calculation methods remain the same throughout the analysis period.

Linear regressions with time are analyzed to detect temporal trends in the data. The $p$ value of the $F$-test on each linear regression is calculated assuming each data point is statistically independent. Linear regressions with time are reported only if the $p$-value is less than 0.10 ; indicating at least a $90 \%$ confidence level. For each reported temporal regression the 
slope, $r^{2}$ value, and $p$-value are given. Most of the regressions reported in this study exceed the $95 \%$ confidence level $(p<0.05)$ and some meet or exceed the $99 \%$ confidence level $(p \leq 0.01)$.

The multiple linear regression analysis begins by applying the Lee and Lwiza ${ }^{43}$ approach of regressing annual maximum hypoxic volume in LIS with February-May LIS-average chlorophyll, July-August average wind speed, maximum monthly LIS discharge from February through May, and February-May LIS-average surface total nitrogen. The Lee and Lwiza ${ }^{43}$ results have been reproduced for the original 1995-2004 study period and are compared with new results for the extended 1994-2018 analysis period.

Further analysis seeks multiple linear regression models for response $(\mathrm{Y})$ variables including March-August depth-averaged total nitrogen concentrations at station A4, FebruaryMay LIS-average chlorophyll, August near-bottom dissolved oxygen and AOU at Station A4, and annual maximum hypoxic area and volume. The 12 candidate regression factors (X variables) are annual NY and CT WWTP nitrogen loads, August direct WLIS and March-August ELIS + CLIS nitrogen loads, March-August depth-averaged total nitrogen concentrations at station A4, February-May LIS-average chlorophyll, July-August average wind speed and prevailing wind direction, and August chlorophyll (averaged over the upper-half of the water column), nearbottom temperature, near-bottom salinity, and stratification (characterized with upper-quartile $N^{2}$ ) at station A4. Note that the regression model for total nitrogen omits total nitrogen from the candidate $X$ variables. The regression model for February-May LIS-average chlorophyll omits chlorophyll variables and all August and July-August quantities (because they reflect conditions later in each year) from the candidate X variables. WLIS and ELIS + CLIS river discharge are not included among the $\mathrm{X}$ variables because their variability is included within the direct WLIS and 
ELIS + CLIS nitrogen loads and river-discharge effects on physical conditions are included in temperature, salinity, and stratification variations. Before regressing, each $\mathrm{Y}$ and $\mathrm{X}$ variable is standardized by subtracting its mean and dividing by its standard deviation to calculate its zscore; the means and standard deviations are included in Table S1.

To determine the multiple linear regression model for each $Y$ variable, a forward and backward stepwise regression process is used to add $\mathrm{X}$ variables from the candidate pool that improve the model and remove $X$ variables that do not. The stepwise regressions are accomplished with the built-in MATLAB function "stepwiselm" (description available at https://www.mathworks.com/help/stats/stepwiselm.html). The adjusted $r^{2}$, that diminishes $r^{2}$ according to the number of parameters (regression factors) involved, is used for the criteria to add and remove $X$ variables. Variables that initially raise the adjusted $r^{2}$ by at least 0.02 are added and those that ultimately increase the adjusted $r^{2}$ by less than 0.01 are removed. The 0.01 removal threshold is selected because it is the same as the precision of $r^{2}$ values reported in this study. The adding threshold must be larger than the removal threshold. For this study, results were the same when the adding and removing thresholds were 0.03 and 0.02 , respectively. Similarly, Carro-Calvo et al. ${ }^{45}$ selected a 0.03 adding threshold for the adjusted $r^{2}$ "after trial and error." Larger thresholds resulted progressively fewer X variables and smaller adjusted $r^{2}$ values for the regressions. Alternatively, the Akaike information criterion (AIC) can be used with the "stepwiselm" function to select variables. ${ }^{48}$ For this study, the AIC approach yields the same regression results (as the adjusted $r^{2}$ criteria) with the requirements that added variables initially decrease AIC by at least 0.02 and included variables ultimately do not increase AIC. Regression coefficients (reported in Table S2) are nondimensional since the $z$-scores of the 
$\mathrm{Y}$ and $\mathrm{X}$ variables are regressed. The dimensional form of the regression coefficients can be calculated by multiplying by the ratio of the corresponding $\mathrm{Y}$ and $\mathrm{X}$ standard deviations (in Table S1). The $r^{2}$, adjusted $r^{2}$, and $p$-values of the $F$-statistic for the final regression models are reported in Table S2. The $p$-values of all of the reported multiple regression models are less than 0.01 . The multiple linear regression time series are graphed with the corresponding observations in Figure S1.

Monthly-averaged results for the August 2006-2099 forecasts of the CESM Large Ensemble Project ${ }^{52}$ were accessed via the Earth System Grid (www.earthsystemgrid.org). Thirty ensemble members for the representative concentration pathway 8.5 (RCP8.5) forcing (following CMIP5 protocols) are averaged together to produce ensemble-mean time series of water temperature, oxygen saturation concentration, and oxygen at the CESM ocean grid cell geographically located within Long Island Sound. It should be noted that the coarse (nominally $1^{\circ}$ latitude) grid resolution and land-ocean mask precludes resolving estuaries such as LIS and estuarine hypoxia. CESM oxygen concentrations have little variation through the water column and do not exhibit hypoxia at the selected location (or at other nearby coastal grid cells). Consequently, this analysis focuses on water temperature and oxygen saturation concentrations. For both variables, anomalies are calculated relative to 2006 values (the first forecast year). 
Table S1 Means and standard deviations for all variables graphed vs. time in Figures 2 and 3. The monthly averaging interval and units are listed. Water temperature, salinity, stratification (assessed with $N^{2}$ ), total nitrogen, upper-water-column chlorophyll, and oxygen concentrations are at station $\mathrm{A} 4$.

\begin{tabular}{|c|c|c|c|c|}
\hline Variable & Months & Mean & $\begin{array}{l}\text { Standard } \\
\text { deviation }\end{array}$ & Units \\
\hline NY WWTP nitrogen load & Annual & 3.73 & 0.85 & $10^{6} \mathrm{~kg} \mathrm{year}^{-1}$ \\
\hline CT WWTP nitrogen load & Annual & 2.32 & 0.82 & $10^{6} \mathrm{~kg}$ year $^{-1}$ \\
\hline NY + CT WWTP nitrogen load & Annual & 6.04 & 1.54 & $10^{6} \mathrm{~kg}$ year $^{-1}$ \\
\hline Direct WLIS nitrogen load & Aug & 2.43 & 1.26 & $10^{6} \mathrm{~kg} \mathrm{year}^{-1}$ \\
\hline ELIS + CLIS nitrogen load & Mar-Aug & 23.3 & 5.31 & $10^{6} \mathrm{~kg}$ year $^{-1}$ \\
\hline WLIS river discharge & Mar-Aug & 0.62 & 0.32 & $\mathrm{~km}^{3}$ year $^{-1}$ \\
\hline ELIS + CLIS river discharge & Mar-Aug & 28.92 & 11.47 & $\mathrm{~km}^{3}$ year $^{-1}$ \\
\hline Wind speed & Jul-Aug & 3.39 & 0.26 & $\mathrm{~m} \mathrm{~s}^{-1}$ \\
\hline Prevailing wind direction & Jul-Aug & 210 & 14 & ${ }^{\circ}$ True \\
\hline Near-surface temperature & Aug & 22.96 & 0.73 & ${ }^{\circ} \mathrm{C}$ \\
\hline Near-bottom temperature & Aug & 20.94 & 1.06 & ${ }^{\circ} \mathrm{C}$ \\
\hline Near-surface salinity & Aug & 26.00 & 0.79 & PSS \\
\hline Near-bottom salinity & Aug & 26.76 & 0.63 & PSS \\
\hline Bulk $N^{2}$ & Aug & 0.33 & 0.13 & $10^{-3} \mathrm{~s}^{-2}$ \\
\hline Upper-quartile $N^{2}$ & Aug & 0.41 & 0.15 & $10^{-3} \mathrm{~s}^{-2}$ \\
\hline Near-surface total nitrogen & Mar-Aug & 0.61 & 0.10 & $\mathrm{mg} \mathrm{L}^{-1}$ \\
\hline Near-bottom total nitrogen & Mar-Aug & 0.50 & 0.11 & $\mathrm{mg} \mathrm{L}^{-1}$ \\
\hline Depth-average total nitrogen & Mar-Aug & 0.55 & 0.10 & $\mathrm{mg} \mathrm{L}^{-1}$ \\
\hline Chlorophyll (upper-water-column) & Aug & 4.27 & 4.15 & $\mu \mathrm{g} \mathrm{L}^{-1}$ \\
\hline LIS-average chlorophyll & Feb-May & 6.11 & 3.83 & $\mu \mathrm{g} \mathrm{L}^{-1}$ \\
\hline Near-surface oxygen saturation & Aug & 7.41 & 0.18 & $\mathrm{mg} \mathrm{L}^{-1}$ \\
\hline Near-bottom oxygen saturation & Aug & 7.63 & 0.16 & $\mathrm{mg} \mathrm{L}^{-1}$ \\
\hline Near-bottom oxygen & Aug & 2.06 & 1.04 & $\mathrm{mg} \mathrm{L}^{-1}$ \\
\hline Near-bottom AOU & Aug & 5.57 & 1.11 & $\mathrm{mg} \mathrm{L}^{-1}$ \\
\hline Hypoxic area & Annual & 430 & 239 & $\mathrm{~km}^{2}$ \\
\hline Hypoxic volume & Annual & 2.06 & 2.14 & $\mathrm{~km}^{3}$ \\
\hline
\end{tabular}


Table S2 Multiple linear regression results for $Y$ variables: total nitrogen (Avg TN), Februarychlorophyll (Feb-May Chl), August dissolved oxygen (DO), AOU and annual maximum hypoxic area and volume (shown in Figure 3 ). Included $X$ variables are drawn from the data in Figure 2 and improve the regression models. $X$ and $Y$ variables are standardized (indicated by the $z($ ) notation signifying the $z$-score) with the corresponding means and standard deviations (Table S1). Regression coefficients are dimensionless. The $r^{2}$, adjusted $r^{2}\left(\operatorname{Adj} r^{2}\right)$, and $p$-value of the regression $F$-statistic are reported.

\begin{tabular}{|c|c|c|c|c|}
\hline $\begin{array}{l}\text { Standardized } \\
\text { Y variables }\end{array}$ & $\begin{array}{l}\text { Multiple linear regression model with standardized X } \\
\text { variables }\end{array}$ & $r^{2}$ & $\underset{r^{2}}{\text { Adj }}$ & $p$ \\
\hline $\mathrm{z}(\operatorname{Avg} \mathrm{TN})$ & $\begin{array}{l}+0.62 \mathrm{z}(\text { CT WWTP })-0.76 \mathrm{z} \text { (WLIS load })+0.90 \mathrm{z} \text { (Wind } \\
\text { speed }) \quad+0.97 \mathrm{z}(\text { Feb-May Chl })-0.51 \mathrm{z}(\text { Bot sal })\end{array}$ & 0.65 & 0.54 & 0.003 \\
\hline z(Feb-May Chl) & $+0.72 \mathrm{z}(\mathrm{NY}$ WWTP $)-0.92 \mathrm{z}(\mathrm{CT}$ WWTP $)$ & 0.50 & 0.45 & 0.001 \\
\hline $\mathrm{z}(\mathrm{DO})$ & $\begin{array}{l}+0.39 \mathrm{z} \text { (WLIS load) }-0.32 \mathrm{z} \text { (Wind dir) }-0.64 \mathrm{z} \text { (upper- } \\
\text { quartile } N^{2} \text { ) }\end{array}$ & 0.65 & 0.60 & $>0.001$ \\
\hline $\mathrm{z}(\mathrm{AOU})$ & $\begin{array}{l}-0.33 \mathrm{z}(\text { WLIS load })+0.31 \mathrm{z}(\text { Wind dir })+0.70 \mathrm{z} \text { (upper- } \\
\left.\text { quartile } N^{2}\right)\end{array}$ & 0.69 & 0.64 & $>0.001$ \\
\hline $\begin{array}{l}\mathrm{z}(\text { Hypoxic } \\
\text { Area })\end{array}$ & $\begin{array}{l}+0.74 \mathrm{z}(\text { CT WWTP })-0.51 \mathrm{z}(\text { ELIS + CLIS load }) \\
+0.66 \mathrm{z}(\text { Feb-May Chl })\end{array}$ & 0.50 & 0.41 & 0.006 \\
\hline z(Hypoxic Vol.) & $\begin{array}{l}+0.31 \mathrm{z}(\text { CT WWTP })-0.56 \mathrm{z}(\text { ELIS + CLIS load }) \\
+0.82 \mathrm{z} \text { (Wind speed })-0.30 \mathrm{z}(\text { Aug Chl }) \\
+1.33 \mathrm{z}(\text { Feb-May Chl })-0.67 \mathrm{z}(\text { Bot sal })\end{array}$ & 0.79 & 0.71 & $>0.001$ \\
\hline
\end{tabular}



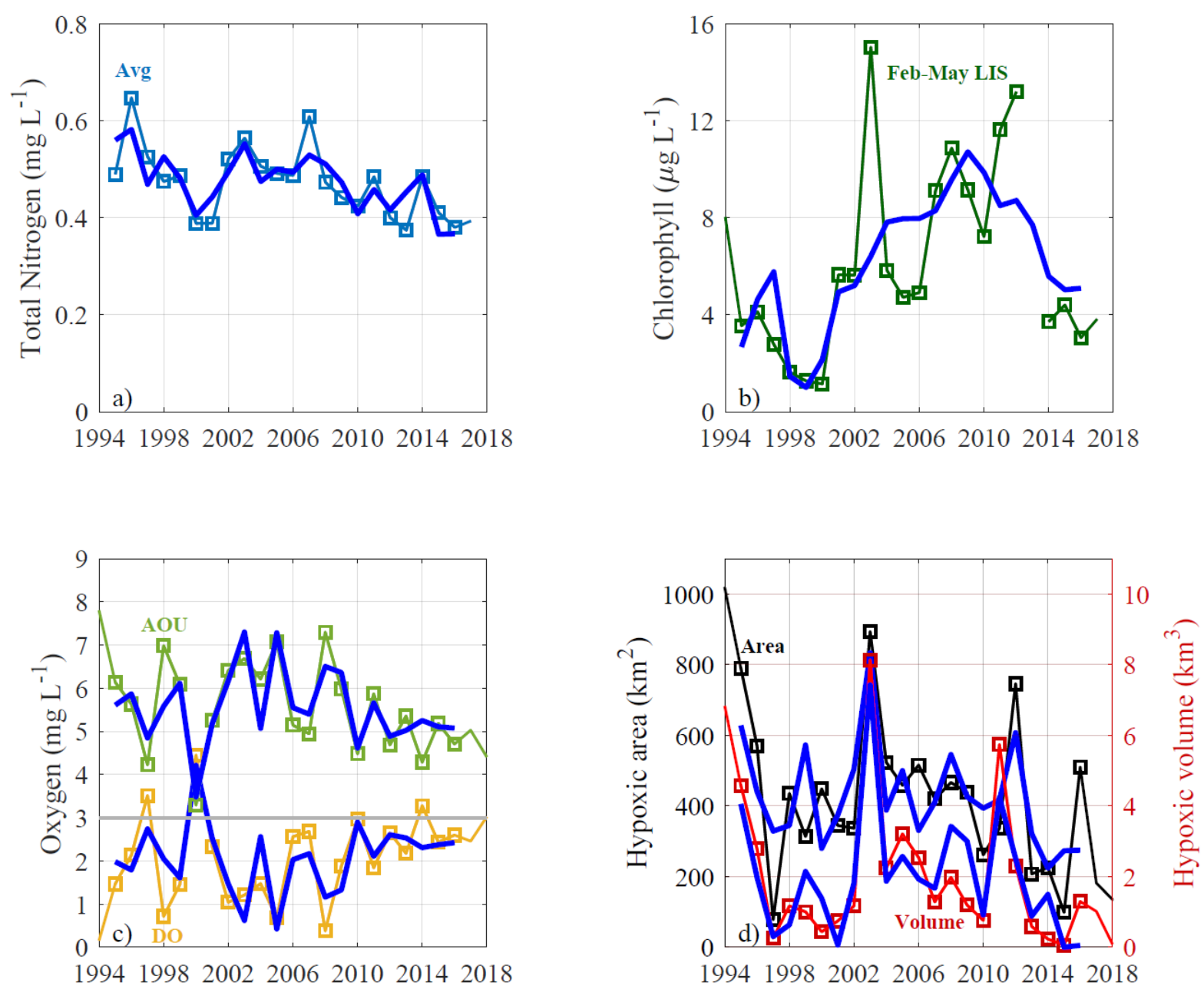

Figure S1 Multiple linear regression time series and observed time series of a) March-August depth-averaged (Avg) total nitrogen concentrations at station A4 in WLIS, b) February-May LISaverage chlorophyll, c) near-bottom dissolved oxygen (DO) and apparent oxygen utilization (AOU), and d) maximum hypoxic area and volume. Regression results (from Table $\mathrm{S} 2$ and then dimensionalized with means and standard deviations in Table S1) are shown with thick blue lines. Observed data points used in the regressions are marked with squares and the full observed time series (also included in Figure 3 ) are shown with thin lines. 